\title{
Aprende-se com as Empresas Japonesas? - Estudo Comparativo entre Empresas Brasileiras e Mexicanas( ${ }^{(1)}$
}

\author{
Maria Tereza Leme Fleury \\ Afonso Fleury
}

\section{RESUMO}

O objetivo deste trabalho é estudar o processo de aprendizagem em empresas brasileiras e mexicanas, processo este provocado pela interação com empresas multinacionais clientes; mais especificamente, pesquisaremos as relações entre empresas subsidiárias japonesas e suas fornecedoras locais no Brasil e no México, analisando como e em que estas influenciam o processo de aprendizagem das empresas locais. À medida que as empresas japonesas são consideradas berço do desenvolvimento de muitas das técnicas atuais de gestão da qualidade e de gestão de pessoal, um estudo com base em survey realizado em empresas nos dois países pode trazer contribuições interessantes a este debate.

Palavras-chaves: aprendizagem organizacional; empresas japonesas; empresas brasileiras e mexicanas; transferência de tecnologia.

\begin{abstract}
The Japanese corporations are usually considered as creators of the newest approaches and methods to manage production systems and human resources. To understant the role of Japanese enterprises in the diffusion of such approaches and methods, we analysed the learning process that occurs in Brazilian and Mexican firms as a consequence of their relationship with Japanese subsidiaries for which they supply parts and components. We analyse whether and how learning processes are induced by that dynamics based on field research conducted among local firms, both in Brazil and Mexico. The main conclusion is that the Japanese subsidiaries are not the main actors in the diffusion of Japanese inspired techniques among local enterprises.
\end{abstract}

Key words: learning organization; japanese firm; brazilian and mexican firms; technology transfer. 


\section{APresentaçÃo}

Um dos maiores desafios das empresas em países em desenvolvimento é aumentar a velocidade da aprendizagem organizacional e tecnológica, visando à sua entrada e permanência em mercados globalizados.

Neste sentido, a dinâmica das relações entre empresas locais e empresas subsidiárias de multinacionais instaladas no país pode vir a se constituir em poderoso fator de aprendizagem. As empresas multinacionais, atrizes centrais do processo de globalização, podem potencializar a aprendizagem das empresas locais através de práticas de transferência de tecnologia e políticas de compras. O seu âmbito de influência não se restringiria ao nível das empresas, mas, em última instância, incluiria regiões e mesmo países.

O objetivo deste trabalho é estudar este processo de aprendizagem em empresas brasileiras e mexicanas, processo provocado pela interação com as empresas clientes; mais especificamente, pesquisaremos as relações entre empresas subsidiárias japonesas e suas fornecedoras locais, no Brasil e no México, analisando como e em que estas influenciam o processo de aprendizagem das empresas locais. À medida que as empresas japonesas são consideradas berço do desenvolvimento de muitas das técnicas atuais de gestão da qualidade, de produtividade e de gestão de pessoal, um estudo focando as suas interações com as empresas fornecedoras locais possibilita encaminhar empiricamente a discussão proposta neste texto.

A nosso ver, na perspectiva das empresas de países em desenvolvimento, o entendimento desses temas é fundamental para a definição de estratégias empresariais, visando a propiciar a capacitação local. Isto é particularmente relevante para empresas de países como o Brasil e o México, cujos processos de industrialização foram e são altamente dependentes das empresas multinacionais.

Com esses objetivos, o trabalho foi estruturado nas seguintes partes: iniciamos com uma discussão sobre a reestruturação produtiva no atual contexto de globalização e o advento da economia baseada em conhecimento; situaremos a seguir, num breve apanhado, o processo de industrialização recente do Brasil e do México, para então apresentarmos os dados de uma pesquisa empírica realizada entre empresas nos dois países e encaminhar algumas conclusões. 


\section{O Contexto de Globalização e o Advento da Empresa Baseada em CONHECIMENTO}

No novo contexto de economia globalizada, as perspectivas de cada país são função das capacitações adquiridas por seus elementos constitutivos: pessoas, empresas, instituições. As capacitações organizacionais e tecnológicas são particularmente importantes, quando se descortina o advento de uma "economia baseada em conhecimento" (OECD, 1996).

Essa nova economia tem como personagens principais os países da chamada Tríade (Estados Unidos, Europa e Japão) e as grandes empresas transnacionais ou globais (TNCs). Todos os países industrialmente avançados (Industrialized Advanced Countries - IACs) têm o seu próprio grupo de empresas campeãs nacionais, que assumem os encargos de avançar sobre os mercados estrangeiros e defender os mercados locais. Esse movimento de internacionalização tem sido tão importante que muitas outras empresas, localizadas em IACs, decidiram recentemente dele participar, pelo menos em termos financeiros. Michalet (1995, p. 92) constatou que, para as empresas, as estratégias financeiras têm sido as mais importantes "na medida em que através de aquisições é possível superar as barreiras de entrada e ter o direito de participar dos oligopólios internacionais, mesmo que a preços muito altos. Trata-se de uma decisão necessária para os retardatários no jogo da globalização. É um modo de saltar sobre os estágios regulares de crescimento multinacional que exige muito tempo".

Admite-se, também, que após esse movimento de reorganização do controle financeiro das empresas produtoras de nível mundial, um novo contexto se deve estabelecer, no qual o desempenho econômico de países e empresas dependerá, de maneira decisiva, de suas capacitações em termos de conhecimento e aprendizagem. Foray e Lundvall (1996, p. 12) argumentam que "estão ocorrendo grandes mudanças no modo de produzir e distribuir conhecimento; isto afeta toda a economia, e exige o repensar suas instituições fundamentais [...] Os mais relevantes temas políticos da nossa era: globalização da economia, subdesenvolvimento nos países pobres, a crescente polarização nos países ricos, assim como os limites ambientais ao crescimento econômico, não podem ser entendidos e trabalhados adequadamente sem que se repense a economia, tendo como foco a aprendizagem e o conhecimento".

Por outro lado, os novos países industriais (NICs) estão sendo envolvidos num jogo, cujas regras não estão bem consolidadas e para o qual eles não estavam adequadamente preparados. Isto demanda novas estratégias e políticas. Os governos locais num passado recente estavam estabelecendo regras e regulamentos para 
disciplinar a atuação do capital estrangeiro; estão agora profundamente preocupados em atrair investimentos produtivos estrangeiros, mesmo tendo de arcar com altas despesas associadas à criação de uma infra-estrutura local que potencie a competitividade das subsidiárias em face da competição global.

Esses países estão ainda preocupados em estabilizar as operações dessas empresas no mais longo prazo possível, para que se torne viável a internalização do conhecimento organizacional e tecnológico a elas associado. Isto é essencial para criar as condições mínimas para que esses países tenham melhores trunfos para negociar na nova economia baseada em conhecimento.

À medida que as tradicionais vantagens competitivas desses países, como recursos naturais abundantes, cedem lugar ao conhecimento, à competência instalada em setores, em empresas (Porter, 1990), os esforços envidados no sentido da aprendizagem se tornam fundamentais. Hamel e Prahalad (1990), ao proporem o conceito de core competence para análise das vantagens competitivas das empresas, enfatizam este aspecto da aprendizagem coletiva: "competências chave significa aprendizagem coletiva nas organizações, especialmente no que diz respeito a coordenar diversas habilidades de produção e integrar múltiplas correntes tecnológicas". Numa obra mais recente Hamel e Prahalad (1994) comentam que uma companhia precisa ser vista não apenas como portfolio de produtos ou serviços, mas também como um portfolio de competências.

No âmbito deste trabalho, procuraremos analisar como empresas de países que estão enfrentando esses desafios, como o Brasil e o México, procuram aprender através da interação com a empresa multinacional cliente.

\section{O Processo de Industrialização Recente do México e do Brasil: 1980/94}

Em termos gerais, parece correto afirmar que os processos de industrialização mexicano e brasileiro seguiram trajetórias convergentes, embora distintas, desde o fim da II Guerra até a crise da dívida externa, no início da década de 80. México e Brasil foram os casos latino-americanos mais bem sucedidos de industrialização por substituição de importações no período, numa época em que as respectivas indústrias apresentaram altas taxas de crescimento. Embora as políticas econômicas desses países fossem inspiradas pelos mesmos objetivos, o Brasil logrou, comparativamente, maior integração e diversificação de seu parque industrial.

No entanto a crise dos anos 80 e as formas como a ela reagiram os governos brasileiro e mexicano levaram a um progressivo afastamento das trajetórias de 
industrialização. A explosão da crise da dívida dos países em desenvolvimento no México, em 1982, a promoção de Zonas de Processamento de Exportações (ZPEs) pelo governo mexicano e o baixo custo do trabalho naquele país levaram a um impressionante crescimento das chamadas indústrias maquiladoras. De outro lado, dada a proximidade com a economia americana, as políticas de abertura comercial e sobrevalorização cambial (a partir de 1988) levaram a um brutal incremento do coeficiente de importação da indústria manufatureira nacional. O novo perfil da estrutura industrial provocado pelo crescimento da maquila, em paralelo com a desindustrialização, está expresso na relação dos volumes de emprego. Em 1994, a indústria manufatureira mexicana (doméstica) não empregava mais do que 800.000 trabalhadores (contra 1,1 milhão em 1981), ao passo que o emprego nas cerca de 2.200 empresas maquiladoras alcançava a marca de 540.000 emprega$\operatorname{dos}^{(2)}$.

Comparativamente, a indústria manufatureira brasileira foi mais preservada na crise dos anos 80. Em primeiro lugar, a crise da dívida não foi enfrentada com soluções desindustrializantes como a adoção de $\mathrm{ZPEs}^{(3)}$ e de abertura comercial abrupta. Pelo contrário, para uma parte significativa da indústria manufatureira brasileira, a saída para a crise e estagnação do mercado interno na década de 80 foi buscada no crescimento das exportações e progressiva ocupação de mercados externos. Não apenas a política industrial manteve alta a proteção à indústria brasileira, até 1990, mas a política cambial e incentivos fiscais favoreceram as exportações. Dessa forma, embora a indústria tenha perdido participação no produto interno, sua contribuição para a geração de superávits comerciais, até a adoção do Plano Real, foi extremamente significativa.

Os limites da guinada mexicana em direção à maquila parecem claros. Apesar de apresentar números impressionantes de exportações (US\$ 22 bilhões, em 1993), as ZPEs mexicanas contribuem relativamente pouco para a balança comercial (superávit de US\$ 5 bilhões), já que importam a quase totalidade de seus insumos - 98\% (Abud, 1996). O baixo valor agregado por esta atividade advém de que ela consiste principalmente em processos de montagem, baseados no uso intensivo de mão-de-obra qualificada e na utilização de métodos que já foram qualificados de fordismo primitivo. Segundo alguns autores (e. g.: Abud, 1996), o mais preocupante estaria na maquilição da indústria nacional. Com a liberalização comercial e apreciação cambial, a indústria nacional está ampliando rapidamente a substituição de insumos internos por insumos importados. Por exemplo, a porcentagem do valor agregado pela indústria automobilística mexicana caiu de $35 \%$, em 1985, para 29\%, em 1992, devido à liberalização e à redução dos índices obrigatórios de nacionalização. No entanto parece-nos que a ampla adoção de outros regimes especiais de subcontratação internacional no México, fora do tradicional esquema maquilador (Gonçalvez-Arechiga e Ramirez, 1990), já no final 
dos anos 80 , além da integração regional da economia mexicana à economia norte-americana e canadense, colocam um forte obstáculo à continuidade de uma manufatura doméstica nos termos em que esta se estruturou e se reproduziu. Em outros termos, no quadro de consolidação do Nafta, a integração da indústria manufatureira mexicana com a indústria daquelas economias tende a se impor sobre a integração com fornecedores e prestadores de serviços nacionais.

Em contraste com a evolução de sua contraparte mexicana, a indústria manufatureira brasileira, desde a crise de 1982, e até recentemente, apresentou impressionante incremento na produção de superávits comerciais. Estímulos governamentais às exportações e restrições às importações levaram o setor manufatureiro a ser o principal responsável pela sustentação da posição superavitária da balança comercial brasileira. A indústria de autopeças, bem representada na amostra de nossa pesquisa, é emblemática desse período. Partindo de valores inexpressivos em 1974, o segmento dos produtos independentes de autopeças superou a marca de US\$ 2 bilhões em exportações no final dos anos 80. No conjunto, o setor automotor gerava, no início dos anos 90 , superávits comerciais que se aproximavam de US\$ 4 bilhões.

Após o evento da abertura dos mercados brasileiros ao comércio internacional, em 1990, a indústria brasileira vem enfrentando desafios, cujas características se têm alterado rapidamente com o tempo. Assim, no período 1990-1994, apesar das políticas de abertura propostas pelo Governo, a dinâmica do funcionamento da indústria local não foi alterada de maneira mais significativa, a não ser em setores muito específicos, como o automotor e o de eletrodomésticos, que passaram a sofrer a concorrência das importações. Apesar da abertura, as condições políticas e econômicas que prevaleciam não eram ainda atraentes para maiores investimentos pelas empresas estrangeiras. Com isto, houve tempo e espaço para as empresas locais (tanto as nacionais quanto as subsidiárias) investirem em modernização, especialmente no plano organizacional, com a adoção de modernos métodos de gestão de origem japonesa, com apoio do Governo através do PBQP (Fleury e Humphrey, 1993). Somente com a adoção do Plano Real, sustentado na ancoragem cambial da moeda, num contexto de abertura comercial, é que se inicia um significativo processo de crescimento das importações de manufaturados. Em 1995, pela primeira vez em mais de quinze anos, a economia brasileira voltou a apresentar déficit na balança comercial. Ainda assim, os efeitos desse processo, no caso brasileiro, parecem distintos daqueles do caso mexicano, em que a internacionalização do fornecimento de componentes se tornou preponderante.

Outro ponto a ser mencionado diz respeito às características do sistema de gestão de cada país. Embora correndo o risco de generalizações grosseiras, pode-se afirmar que, tradicionalmente, as empresas dos dois países apresentavam siste- 
mas de gestão bastante centralizadores, com estruturas altamente hierarquizadas e baixa participação dos empregados, reduzida preocupação com a qualificação da força de trabalho e altos índices de rotatividade (Lawrence, 1996; Rodriguez, 1996). Esse quadro começou a se alterar, nos anos 80, com a abertura de mercado e a necessidade de as empresas reverem seus sistemas de gestão para melhorar custo, produtividade e qualidade de seus produtos.

Neste estudo procuraremos investigar em que medida as empresas multinacionais de origem japonesa que, como já mencionamos, são consideradas berço das modernas técnicas de gestão de qualidade e produtividade, estão provocando esta capacitação das suas empresas fornecedoras locais no Brasil e no México, através da transferência de tecnologia e de técnicas de gestão.

\section{Estudo Empírico das Empresas Fornecedoras locais Brasileiras e Mexicanas}

Objetivando refletir empiricamente sobre as questões propostas neste trabalho, apresentamos os dados de um estudo realizado nas empresas industriais brasileiras e mexicanas, que são fornecedoras de empresas subsidiárias japonesas nos respectivos países.

\section{Aspectos Metodológicos}

A pesquisa foi realizada em amostra de 56 empresas brasileiras e 61 mexicanas fornecedoras de subsidiárias japonesas. A pesquisa de campo ocorreu no segundo semestre de 1994 e início de 1995, tendo feito parte de um projeto mais amplo coordenado pelo Institute of Developing Economies, instituição ligada ao MITI (Ministério do Comércio e da Indústria do Japão) ${ }^{(4)}$. Em 1996, os autores deste artigo visitaram algumas das empresas mexicanas estudadas e discutiram o relatório com a equipe mexicana; aprofundaram também o estudo das empresas brasileiras ${ }^{(5)}$.

No caso brasileiro, 56 empresas foram pesquisadas, das quais 52 se localizavam no Estado de São Paulo. A grande maioria era de controle brasileiro, na época da pesquisa.

A amostra mexicana foi distribuída entre quatro diferentes regiões do país, estando representadas tanto as regiões de industrialização mais antiga (por exemplo a região central) e voltadas para o mercado interno, como as regiões de industrialização recente, com base em maquilas e voltadas para a exportação (por exemplo a região de fronteira norte). 
Com relação à classificação da amostra por setor (Figura 1), podemos verificar que a proporção entre empresas eletro-eletrônicas e metal-mecânicas permanece semelhante em ambos os países. As empresas eletro-eletrônicas representaram $12,5 \%$ na amostra brasileira e $16,39 \%$ na amostra mexicana. Já as do setor metal-mecânico representaram, respectivamente, 69,64 \% e 65,57\%.

Figura 1: Caracterização da Amostra por Setor

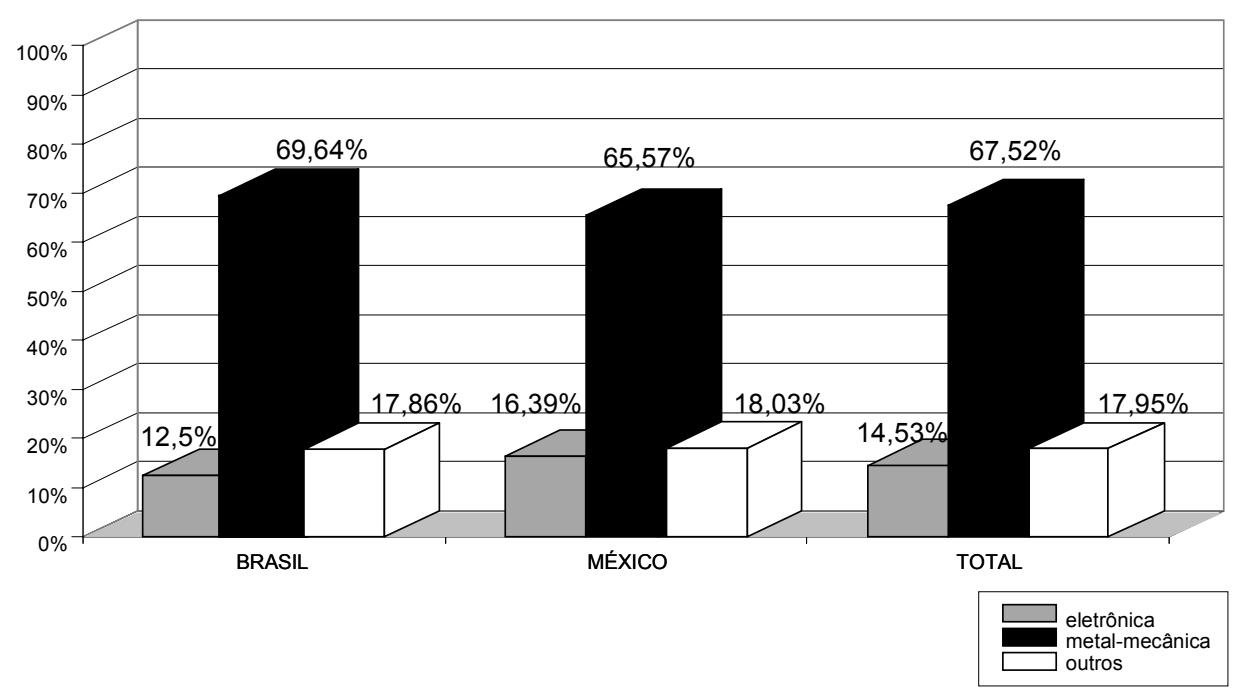

Figura 2: Caracterização da Amostra por Porte

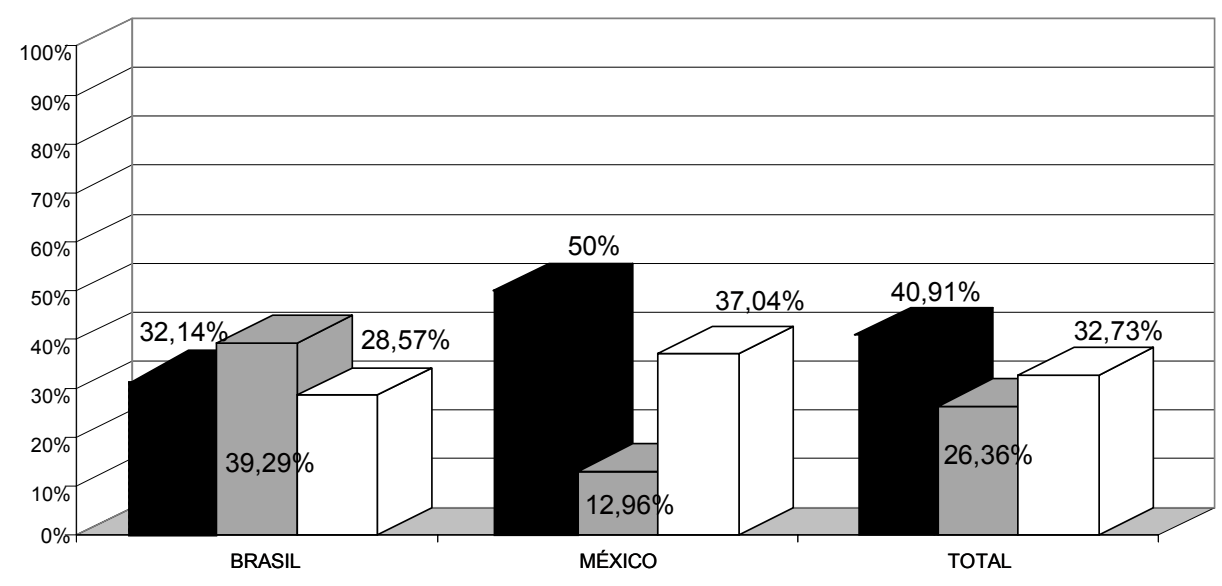


Em termos de tamanho (Figura 2), a amostra brasileira foi distribuída assim: 18 pequenas empresas (até 100 empregados), 22 médias (até 500 empregados) e 16 grandes empresas (mais de 500 empregados). No caso mexicano, a maior parcela era composta de pequenas empresas (27).

A partir da análise de informações levantadas nos questionários aplicados na amostra de empresas nos dois países e das entrevistas realizadas, os seguintes temas serão discutidos:

- como ocorre o processo de transferência de tecnologia;

· como ocorre o processo de transferência de técnicas de gestão da qualidade;

- como ocorre o processo de adoção de técnicas de gestão de pessoal pelas empresas fornecedoras locais.

\section{O Processo de Transferência de Tecnologia}

O primeiro ponto a ser analisado diz respeito ao processo de transferência de tecnologia pelas empresas subsidiárias japonesas $(\mathrm{SJ})$ e à aprendizagem feita pelas empresas fornecedoras locais (FLs). Observando-se os dados da tabela abaixo, verifica-se que a avaliação do processo de transferência de tecnologia das SJs para as FLs apresenta resultados similares: é pouco significativo em ambos os países.

\begin{tabular}{|l|c|c|}
\hline Recebe assistência da subsidiária japonesa ? & México & Brasil \\
\hline Sim & $40 \%$ & $35 \%$ \\
\hline Não & $60 \%$ & $65 \%$ \\
\hline Total & $100 \%$ & $100 \%$ \\
\hline
\end{tabular}

Os tipos de assistência recebidos pelas empresas fornecedoras locais têm padrão similar, respeitando a seguinte ordem de importância:

- controle de qualidade;

- projeto de produto;

- especificação de materiais;

- custos e finanças.

A maior discrepância observada nas duas amostras foi em termos de assistência para o PPCP - Planejamento, Programação e Controle de Produção, sensivelmente mais importante para as empresas mexicanas do que para as brasileiras. Este 
ponto pode ser justificado também pela maior importância relativa das compras das SJs mexicanas para os fornecedores locais.

O quadro acima pode ser mais bem entendido ao se introduzir a questão do tamanho da empresa local. No caso brasileiro, entre as pequenas empresas, $39 \%$ consideram relevante o suporte tecnológico provido pela SJ; esta porcentagem cai para $23 \%$ entre as empresas médias. A porcentagem aumenta para as empresas grandes, mas a natureza da relação muda. São estes os casos em que a SJ usa a capacitação tecnológica das empresas locais; ou seja, a relação é mais nivelada. No Brasil, as SJs não são empresas de porte muito maior que os seus fornecedores locais de maior porte. Por exemplo, uma empresa local, fabricante de assentos para automóveis, com 1.500 funcionários, considera que sua relação com a Toyota do Brasil é uma relação entre iguais, o que absolutamente não é o caso das outras empresas montadoras para as quais fornece (VW, Ford e Fiat).

A relação das fornecedoras mexicanas com as SJs (especialmente Nissan, Honda, Panasonic e Harada-Hia) envolve conteúdo maior de pedidos sob encomenda. No caso brasileiro, ocorre o inverso: a amostra estudada no Brasil revelou maior número de SJs como compradoras impessoais de componentes padronizados universais. Nestes casos, o espaço para transferência de tecnologia e para influenciar os critérios de gestão da produção é menor, a não ser pelo lado das exigências associadas à qualidade de entrega, como veremos depois.

Foi observado ainda que o padrão de relações entre FLs e SJs se altera no decorrer do tempo, na direção inversa ao esperado, tornando-se menos intenso e mais conflituoso. No caso brasileiro, constatou-se que quando o FL estabelece vínculos com uma SJ para produzir de acordo com as suas especificações, recebe forte apoio da SJ durante o processo de implantação do processo produtivo, que vai resultar no produto demandado pela subsidiária japonesa. Mas depois de aprovado o try-out, a relação se enfraquece e, na maioria dos casos, praticamente desaparece, mantendo-se exclusivamente na condição de comprador. A única exceção identificada foi a Honda e, numa escala bem menor, a Yamaha.

O mesmo parece ocorrer no caso mexicano. As informações obtidas indicam que metade das empresas mexicanas dizem participar do processo de projeto do produto junto com a SJ mas que, depois, a assistência técnica recebida é pouco relevante. Parece lícito interpretar que a transferência de tecnologia de produto e de processo também é concentrada nesse período de tempo.

Uma possível explanação para a deterioração nas relações entre as empresas japonesas e as empresas locais derivou dos constantes processos de renegociação de preços, em função das instabilidades macroeconômicas e dos sucessivos pla- 
nos de ajuste. As empresas japonesas foram consideradas as mais duras em termos de negociação, e isto pode ter acarretado situações delicadas, especialmente nas relações com as pequenas empresas locais. O possível conflito vai afetar a transferência de tecnologia, de maneira geral.

Nesse processo de transferência de conhecimentos tecnológicos, as subsidiárias japonesas utilizam mecanismos diferentes nos dois países, como demonstra a tabela abaixo.

\begin{tabular}{|l|c|c|}
\hline Mecanismo para transferência de tecnologia & México & Brasil \\
\hline Treinamento na subsidiária japonesa & $35 \%$ & $14 \%$ \\
\hline Envio de técnicos para a subsidiária & $12 \%$ & $17 \%$ \\
\hline Documentação escrita & $19 \%$ & $30 \%$ \\
\hline Total de empresas que recebem tecnologia & $40 \%$ & $35 \%$ \\
\hline
\end{tabular}

Observamos que os tipos de mecanismo de transferência de tecnologia utilizados para os FLs mexicanos se aproximam mais daqueles propostos para o desenvolvimento de fornecedores do que o que ocorre para o caso brasileiro.

No Brasil, a SJ que buscou com maior dedicação o desenvolvimento de fornecedores locais foi a Honda. Esta chegou ao Brasil, no final da década de 1970, com uma versão local de sua "global network flexifactory" (Mair, 1994). Observou-se grande esforço de construir um tipo de relacionamento diferenciado com os fornecedores locais, visando à sua capacitação tecnológica. Os mecanismos mais utilizados eram (1) seminários estruturados em função de deficiências técnicas que a Honda considerava mais comuns a grupos de fornecedores; e (2) assistência técnica individualizada in loco para fornecedores preferenciais.

Aparentemente o sistema funcionou bem, enquanto não se configuraram situações de crise. Quando isto ocorreu a Honda do Brasil reduziu os seus seminários e passou a privilegiar as grandes empresas locais como fornecedores preferenciais. Isto acarretou problemas de grande monta para algumas pequenas empresas que haviam escolhido estratégias dependentes da subsidiária japonesa.

Dados adicionais sobre as fontes de informação tecnológica utilizadas pelas empresas brasileiras e mexicanas podem proporcionar uma visão mais clara da importância das SJs como indutores de capacitação tecnológica. 


\begin{tabular}{|l|l|}
\hline Fontes de informação & Fontes de informação \\
Empresas mexicanas & Empresas brasileiras \\
\hline Empresas japonesas & Participação em feiras \\
Visitas a outras empresas & Revistas técnicas \\
Participação em feiras & Visitas a empresas estrangeiras \\
Associação industrial & Livros técnicos \\
Revistas técnicas & Participação em seminários \\
Outras empresas & Empresas não-japonesas \\
Consultoria & Consultorias \\
& Universidade \\
& Empresas japonesas \\
& Importacão de produtos \\
\hline
\end{tabular}

Assim, as empresas mexicanas da amostra parecem estar em posição mais dependente das empresas japonesas em termos de desenvolvimento de capacitações tecnológicas e gerenciais.

Em síntese, no início de suas relações com as empresas locais as SJs são altamente seletivas, há longo período de avaliação de capacidades e negociação e forte relacionamento durante a implantação do processo produtivo e a entrega do primeiro lote; a partir de então, as compras são feitas em volumes relativamente pequenos (com exceção da Nissan - México) e mudanças na programação não são raras; há desconfiança em termos de capacidade para manter níveis pré-estabelecidos de qualidade, o suporte técnico não é geral e a comunicação pode ser difícil, devida a outros fatores.

\section{O Processo de Transferência de Técnicas de Gestão de Qualidade}

Como já ressaltado, a gestão da qualidade é uma das áreas em que as empresas brasileiras e mexicanas têm concentrado seus esforços de reestruturação e modernização, com resultados comprovadamente significativos. Não obstante, os resultados das pesquisas que originaram este artigo revelaram ter sido pequeno o papel das SJs no processo de melhoria das práticas de qualidade de seus fornecedores. Em vez da transferência de técnicas de gestão da qualidade, o relacionamento entre SJs e fornecedores brasileiros e mexicanos tem sido marcado, na maioria dos casos, por desconfiança e intervenção direta das SJs, centralizando o processo de controle da qualidade.

No caso brasileiro, a preocupação dos fornecedores da amostra pesquisada com a melhoria de seus padrões de qualidade pode ser demonstrada pelo número de 
departamentos e/ou laboratórios de qualidade do produto, formalmente organizados, que muitos deles mantêm. Cerca de $75 \%$ das empresas da amostra confirmaram a existência dessas áreas em sua estrutura, embora a formalização das práticas de qualidade seja bem maior entre os grandes e médios fornecedores do que entre os pequenos. A maior parte delas demonstrou estar ciente de que a qualidade era o principal fator considerado pelas SJs, ao escolher seus fornecedores; além disso essas empresas consideraram-se capazes de atender a padrões internacionais de qualidade. Em seu favor, os fornecedores brasileiros apresentaram a evidência de terem recebido, em anos recentes, prêmios de qualidade patrocinados por seus clientes (sobretudo não-japoneses). Aproximadamente 63\% das empresas fornecedoras declararam ter recebido prêmios de qualidade de seus clientes brasileiros, norte-americanos e europeus. Também com relação a esse aspecto, a maior premiação concentrou-se entre empresas fornecedoras de grande e médio portes. Quanto às de pequeno porte, metade delas não se considera em condições de atender a requisitos mais exigentes de qualidade.

No entanto a avaliação das SJs sobre a qualidade dos produtos fornecidos pelas empresas brasileiras é oposta à auto-avaliação feita por elas próprias. Na avaliação das SJs sobre quais seriam os principais problemas encontrados em sua relação comercial com os fornecedores brasileiros, a qualidade insatisfatória dos componentes e materiais fornecidos localmente foi, de longe, apontada como o maior deles.

A percepção que as SJs têm da qualidade dos produtos fornecidos pelas empresas brasileiras parece ter afetado substancialmente a divisão de trabalho entre as duas partes com relação à supervisão da qualidade. Embora muitos dos fornecedores estejam envolvidos em contratos de fornecimento com as SJs, pelos quais fazem entregas freqüentes, pressupondo confiança na relação comercial e confiabilidade no produto fornecido, a supervisão da qualidade das entregas ainda é bastante centralizada pelas SJs, quando não nelas internalizada. Cerca de $40 \%$ dos fornecedores da amostra declararam que seus clientes japoneses exercem alguma forma de controle/intervenção direta na supervisão da qualidade do produto fornecido. Essa proporção é ainda maior (50\%) entre pequenas fornecedoras. Os depoimentos das SJs sugerem que, na perspectiva dos clientes japoneses, a falta de autonomia dos fornecedores brasileiros é ainda maior. Mais de $90 \%$ das SJs declararam realizar alguma forma de inspeção amostral de qualidade dos materiais ou componentes fornecidos por empresas brasileiras. Apenas reduzido número de SJs manifestou-se afirmando que os fornecedores eram autônomos e inteiramente responsáveis pelo controle da qualidade (fornecimento com qualidade assegurada). Segundo as SJs, a supervisão de qualidade realizada por fornecedores brasileiros era inferior aos requisitos mínimos. 
Os dados colhidos para o caso mexicano revelam padrão bastante similar. É interessante observar que este padrão de confrontação pode ser ainda mais generalizado. Watanabe (1993) menciona uma pesquisa da JETRO - Japan Export and Trade Organization, a qual constatou que " $70 \%$ das subsidiárias japonesas na Europa estavam insatisfeitas com seus fornecedores locais". O que talvez seja diferente é que, nestes casos, "as empresas japonesas ensinavam aos seus fornecedores locais como reduzir custos e melhorar a qualidade e, dependendo dos resultados, premiavam-nas com contratos de longo prazo" (Watanabe, 1993).

Sumariando os resultados já apresentados, observamos, em primeiro lugar, que as SJs não consideram a qualidade dos produtos e as práticas de qualidade dos fornecedores locais satisfatórias; em segundo, tal percepção acaba por constituir obstáculo para que concedam aos fornecedores maior autonomia na supervisão da qualidade dos componentes e materiais fornecidos às SJs. Em outras palavras, as práticas de qualidade efetivamente prevalecentes na relação de fornecimento (entre SJs e fornecedores) ainda estão longe do modelo de parceria e confiança normalmente associado às empresas japonesas, modelo que implica maior descentralização de responsabilidade aos fornecedores. Tal fato poderia ser visto como situação transitória, não fosse por um terceiro aspecto, também revelado pelos resultados da pesquisa: os fornecedores (especialmente os brasileiros) não consideram sua qualidade como insatisfatória e apresentam os fortes laços com outros clientes (não-japoneses) como evidência de melhoria da qualidade. Esse fosso entre as percepções a respeito da qualidade dos fornecedores brasileiros sugere que a interação entre eles e as SJs tem sido fraca.

Com efeito, considerando que a literatura tem mostrado e documentado o progresso feito por empresas brasileiras na área da qualidade e que as subsidiárias de empresas norte-americanas e européias têm tido importante papel na disseminação dessas práticas junto a seus fornecedores, os resultados da pesquisa parecem indicar poderem as SJs estar bem atrás de multinacionais de outras origens no que diz respeito à transferência de novas práticas e conceitos de gestão e organização para fornecedores brasileiros. Considerando-se ainda a evidência de que mais de $60 \%$ das empresas fornecedoras (incluindo as de pequeno porte) declararam não receber qualquer assistência tecnológica, nem mesmo na área de qualidade, de seus clientes japoneses, a principal conclusão a que se chega com esses resultados é este aparente paradoxo: de maneira geral, excetuando-se poucos casos, a influência das SJs na difusão de técnicas modernas de administração de inspiração japonesa é consideravelmente menor do que a exercida por empresas multinacionais de outras origens. 


\section{O Processo de Transferência de Técnicas de Gestão de Pessoal}

Um último aspecto a ser considerado no processo de transferência de tecnologia diz respeito à transferência e adoção de técnicas de gestão de pessoal.

No Brasil, um primeiro momento na introdução destas técnicas aconteceu ainda no início da década de 80, com a difusão dos Círculos de Controle de Qualidade (CCQs). Os CCQs, nessa época, foram utilizados muito mais como estratégia para incentivar a participação dos operários e melhorar a comunicação interna, coibindo assim a crescente participação do movimento sindical, do que como ferramenta para melhoria da qualidade. Os CCQs, como modismo nas empresas, tiveram curta duração, mesmo porque os traços predominantes dos sistemas de gestão das empresas brasileiras, como descritos no item anterior, ainda se diziam presentes na maioria das empresas; eles passaram a ter importância e significação com a implementação dos programas de qualidade.

No final da década de 80 , as empresas brasileiras começaram a investir seriamente nos programas de qualidade, e as demais técnicas de gestão japonesas assumiram maior relevância. Essa difusão foi bastante generalizada e não restrita a um segmento de empresas, como é o caso mexicano. Corroborando nossa afirmação, observamos que uma pesquisa nacional realizada em 1995 pelo BNDES, compreendendo 1356 empresas brasileiras, representando 15 setores de atividade industrial, constatou que $62 \%$ das empresas brasileiras entrevistadas adotam programas de qualidade total. Por outro lado, $80 \%$ das empresas declararam incentivar seus empregados a apresentarem sugestões para melhoria dos produtos ou processos.

No caso mexicano, a preocupação com os programas de qualidade tomou também impulso no decorrer da década de 80 , principalmente entre as empresas fornecedoras de grandes empresas multinacionais, como é o caso da amostra pesquisada neste estudo. Neste caso, a influência das empresas subsidiárias japonesas foi ainda mais acentuada que no caso brasileiro. Como já mencionamos, $42 \%$ das empresas pesquisadas aprenderam sobre as técnicas gerenciais japonesas através de suas empresas clientes, enquanto que no caso brasileiro, apenas para $17 \%$ da amostra pesquisada esta foi a principal fonte de informações. A introdução de técnicas como o CCQ, caixas de sugestão, é bastante recente, o que ocorreu após o início dos anos 90, para cerca de $60 \%$ das empresas fornecedoras mexicanas entrevistadas.

Entre as empresas fornecedoras locais é possível observar uma taxa de adoção superior entre as empresas mexicanas em relação às suas congêneres brasileiras.

No caso das técnicas que objetivam obter a participação dos trabalhadores para 
a melhoria da qualidade e do processo de trabalho, observamos esta diferença:

\begin{tabular}{|l|c|c|}
\hline & Brasil & México \\
\hline CCQ & $41 \%$ & $52 \%$ \\
\hline Caixa de sugestão & $73 \%$ & $77 \%$ \\
\hline Kaizen & $36 \%$ & $62 \%$ \\
\hline
\end{tabular}

No caso do kaizen, técnica utilizada para obter a melhoria contínua, esta diferença se mostrou mais significativa.

Analisando os dados por setor, observamos que no caso mexicano há diferenças entre as empresas do setor metal-mecânico, que apresentam índices mais elevados de adoção do que as empresas do setor eletrônico. As empresas mexicanas do setor metal-mecânico são fornecedoras das grandes empresas montadoras multinacionais e sua preocupação com a questão da qualidade é significativa. A necessidade de estabilizar a mão-de-obra operacional e comprometê-la com os programas de qualidade é prioritária para essas empresas. Uma empresa por nós visitada, fabricante de chassis, na região de Monterrey, vem procurando desenvolver seu programa de qualidade com um projeto de qualidade de vida dos empregados. Na própria declaração dos princípios da qualidade há menção à "alma, espírito e corpo" necessários para o sucesso do programa. A empresa investe seriamente nas diversas técnicas de participação dos empregados e procura estabilizar seu corpo funcional através de incentivos financeiros e de treinamento. No caso das empresas do setor eletrônico, uma explicação para isto diz respeito ao fato de que a maioria é pequenas empresas.

No caso brasileiro não observamos diferenças significativas entre os setores pesquisados.

Outras técnicas típicas de gestão japonesas como a promoção baseada na senioridade e emprego vitalício, não são adotadas pelas empresas brasileiras e pouco adotadas pelas empresas mexicanas. No caso das empresas fornecedoras mexicanas, $19 \%$ das empresas pesquisadas mencionam ter introduzido a progressão por senioridade, como forma de reduzir o alto turn over de mão-de-obra. Essas técnicas, bastante citadas como constituindo a espinha dorsal do sistema japonês de gestão de pessoal, tiveram razão de ser no contexto econômico e cultural próprio a esse país no período do pós-guerra; entretanto, mesmo aí, a promoção com base em critérios de senioridade vem sendo substituída por critérios de desempenho, em muitas empresas (Fleury e Fleury, 1995).

A implementação de programas de qualidade e produtividade levou tanto as empresas fornecedoras mexicanas, como as brasileiras, a investimentos crescen- 
tes na área de treinamento. Além do tradicional treinamento on the job, que a maioria reportou realizar, $85 \%$ das empresas mexicanas e $71 \%$ das empresas brasileiras afirmaram estar desenvolvendo programas com recursos internos e $47 \%$ das empresas mexicanas e 50\% das empresas brasileiras com recursos externos $^{(6)}$.

Com relação ao treinamento feito com o parceiro japonês, observamos ser esta uma prática pouco utilizada tanto no Brasil como no México. Apenas 7 empresas brasileiras relataram a realização desse tipo de treinamento e nenhuma empresa mexicana; em compensação, 7 empresas mexicanas declararam enviar seus empregados para treinamento no Japão, prática esta adotada apenas por uma das empresas brasileiras.

A questão da educação básica dos trabalhadores é uma das preocupações das empresas brasileiras; $46 \%$ das empresas pesquisadas declararam estar investindo neste tipo de programa. A estratégia adotada pelas empresas mexicanas foi aumentar o requisito de escolaridade da mão-de-obra empregada. $\mathrm{Na}$ amostra pesquisada, os trabalhadores mexicanos têm o primeiro grau completo, o que é considerado um nível elevado para os padrões do país.

Tanto as empresas brasileiras, como as empresas mexicanas, vêm realizando esforços no sentido de estabilizar sua mão-de-obra, conseguindo alcançar índices de turn over abaixo de 10\% anuais, índice considerado baixo para ambos os países.

Em suma, observa-se na amostra de empresas pesquisadas uma mudança no perfil das empresas no que se refere ao sistema de gestão, com a crescente utilização de técnicas de gestão de inspiração japonesa, associadas principalmente aos esforços de melhoria de produtividade e qualidade dos produtos; entretanto as empresas subsidiárias japonesas representam papel muito secundário como indutores deste processo de aprendizagem; ainda no caso das empresas mexicanas, este papel foi um pouco mais relevante do que no caso das empresas brasileiras.

\section{Conclusóes}

O estudo empírico realizado entre empresas brasileiras e mexicanas, fornecedoras de empresas subsidiárias japonesas, possibilitou encaminhar observações interessantes sobre a dinâmica da interação entre empresas e o processo de aprendizagem, nestes dois países.

Entre as empresas brasileiras, um dos resultados significativos foi a percepção 
da existência de laços relativamente fracos entre as subsidiárias japonesas e as fornecedoras brasileiras, seja do ponto de vista institucional, seja do ponto de vista comercial ou tecnológico. Comparando com as relações desenvolvidas por essas empresas brasileiras com empresas multinacionais de outras origens, observa-se que esses laços são mais fortes do que os desenvolvidos com as SJs. Parecenos que a influência de outros grupos estrangeiros na conformação do atual processo de reeestruturação industrial no Brasil é bastante mais significativa que a das empresas multinacionais japonesas.

Com referência à questão de capacitação tecnológica e organizacional das empresas brasileiras, observa-se que um número cada vez mais significativo está implementando processos internos de modernização pela adoção de inovações organizacionais baseadas em técnicas japonesas e de novas tecnologias de produção. Além disto e apesar das dificuldades enfrentadas devido à heterogeneidade da indústria brasileira, empresas líderes, de grande porte, em setores selecionados, estão caminhando na direção de estabelecer redes permanentes com seus fornecedores. Tal processo visa ao estabelecimento de parceria de negócios mais estável, que envolve compartilhar riscos, custos e lucros. No entanto, com exceção da Honda do Brasil, as SJs presentes no país estão bastante atrás neste processo de estabelecimento de redes e desenvolvimento de fornecedores, com transferência de tecnologia e técnicas de gestão da produção.

No caso das empresas mexicanas, a relação das empresas subsidiárias japonesas com as empresas locais é mais forte do que no caso brasileiro. O ser fornecedora de uma empresa japonesa é interessante para a empresa local mexicana pela estabilização de vendas e pela capacitação interna induzida pela empresa japonesa, com suas exigências de qualidade e custo; mesmo o processo de aprendizagem de técnicas de gestão provocado pela SJ é mais significativo entre as empresas mexicanas do que entre as empresas brasileiras. Entretanto o padrão de relações encontrado entre as SJs no México e as fornecedoras locais ainda está longe do padrão encontrado no Japão, ou mesmo em outros países da Ásia, em que a presença das multinacionais japonesas é significativa.

Do ponto de vista das empresas japonesas, a estratégia de relacionamento com eventuais fornecedores locais parece seguir determinados padrões. Quando as empresas não encontram capacitação tecnológica e gerencial desenvolvida na região, a opção pode ser instalar uma empresa do tipo das maquiladoras, em que todos os componentes vêm de fora e a empresa se aproveita da mão-de-obra barata, não realizando qualquer investimento em termos de capacitação local; ou então a empresa procura desenvolver e capacitar uma rede de fornecedores locais. Este parece ser o caso do México. Quando a empresa já encontra certa base tecnológica e gerencial instalada na região, pode optar por formar sua rede de fornecedores e continuar investindo em sua capacitação, ou simplesmente colocar 
seus parâmetros de qualidade e custo, o que induz mudanças nas empresas locais, porém ela mesma pouco investe na capacitação e no processo de aprendizagem da empresa. Este parece ser o caso das empresas brasileiras.

Qualquer tentativa de generalização deste conjunto de estudos de caso para o comportamento de empresas multinacionais, tem de ser considerada em suas devidas proporções. Não obstante, outros estudos que analisaram comparativamente o padrão de relacionamento das subsidiárias japonesas com as comunidades locais chegaram a uma conclusão similar: as empresas japonesas são menos abertas a processos de transferência de tecnologia em geral (Hobday, 1996; Ariffin e Bell, 1997).

Recolocando-se, portanto, a pergunta inicial deste estudo: Aprende-se com as empresas multinacionais japonesas? A resposta parece indicar um sim, com muitas restrições. Neste contexto de crescente globalização produtiva, em que a velocidade de aprendizagem se torna fator importante de competitividade empresarial, potenciar a relação com a empresa cliente, neste processo de transferência de conhecimentos tecnológicos e de técnicas de produção e gestão, pode constituir elemento crucial para o desenvolvimento ou até para a sobrevivência das empresas.

\section{Notas}

${ }^{1}$ Os autores agradecem a Rui Quadros de Carvalho, da UNICAMP, que desenvolveu a pesquisa sobre as empresas fornecedoras brasileiras em conjunto com os autores; agradecem também a Yoichi Koike do Institute of Developing Economies Tokyo e a Clemente Ruiz Duran do Colegio de México.

${ }^{2}$ Segundo Abud (1996), a maquila mexicana é a que emprega o maior número de trabalhadores, entre todos os países que possuem ZPEs.

${ }^{3}$ No Brasil, a possibilidade de implantação de ZPEs, embora tenha vingado legalmente, nunca empolgou quaisquer das correntes dominantes do debate sobre política industrial e de comércio exterior.

${ }^{4} \mathrm{O}$ projeto de pesquisa patrocinado pelo IDE se intitulava The Role of Japanese Direct Investments in Developing Countries, compreendendo investigação nos seguintes países, além do Brasil e México: Filipinas, China, Índia, Coréia do Sul, Taiwan e Malásia. O relatório detalhado do caso brasileiro está em Fleury, Quadros e Fleury (1995). O relatório sobre o caso mexicano foi preparado por Duran (1995).

${ }^{5} \mathrm{Um}$ ponto importante discutido nesta ocasião foi a representatividade das duas amostras. Embora em nenhum dos estudos a amostra seja estatisticamente representativa, no caso mexicano as empresas locais pesquisadas constituem exceções, em termos de desenvolvimento tecnológico e gerencial, quando comparadas ao conjunto das empresas do país. Já no caso brasileiro, as empresas locais pesquisadas se encontram bem na média do padrão de desenvolvimento das empresas 
brasileiras; a comparação com os dados de um estudo mais abrangente conduzido pelo BNDES (1995) nos permite fazer esta afirmação.

${ }^{6}$ Confrontando os dados de nossa pesquisa com aqueles coletados por pesquisa recente realizada pelo BNDES, observamos dados bastante semelhantes para o conjunto das empresas brasileiras pesquisadas neste estudo.

\section{RefERÊnCIAS Bibliográficas}

ABUD, J.

Dívida externa, estabilização econômica, abertura comercial, ingresso de capitais externos e baixo crescimento econômico México 1988-93. São Paulo, 1996. Tese (Doutorado) - Escola de Administração de Empresas de São Paulo, Fundação Getúlio Vargas.

FLEURY, A.;

FLEURY, M. T. L.

Aprendizagem e inovação organizacional : as experiências de Japão, Coréia e Brasil. São Paulo : Atlas, 1995.

FLEURY, A.;

HUMPHREY, J.

Human resources and the diffusion and adaptation of new quality methods in Brazilian manufacturing. Institute of Development Studies, Research Report, n. 24, 1993.

FORAY, D.;

LUNDVALL, B. A.

The knowledge-based economy : from the economics of knowledge to learning economy. Paris: OECD Document, p. 1132, 1996.

FRUIN, W. M.

The japanese enterprise system : competitive strategies and cooperative structures. New York : Oxford University Press, 1992.

\section{LAWRENCE, J.}

Management in México. In: Encyclopaedia of management. London : Routledge, 1996.

MAIR, A.

Honda's global flexifactory network. International Journal of Operations and Production Management, v. 14, n. 3, p. 0623, 1994.

OECD.

Employment and growth in the knowledge-based economy. $\mathrm{Pa}$ ris, 1996.

RODRIGUES, S.

Management in Brazil. In: Encyclopaedia of management. London : Routledge, 1996.

\section{WATANABE, S.}

Growth and structural change of Japanese overseas direct investment : implications for labour and management in host economies. In: BAILEY P.; PARISOTO, A.; RENSHAW, G. Multinationals and employment : the global economy of the 1990's. Geneva : International Labour Office, 1993. 